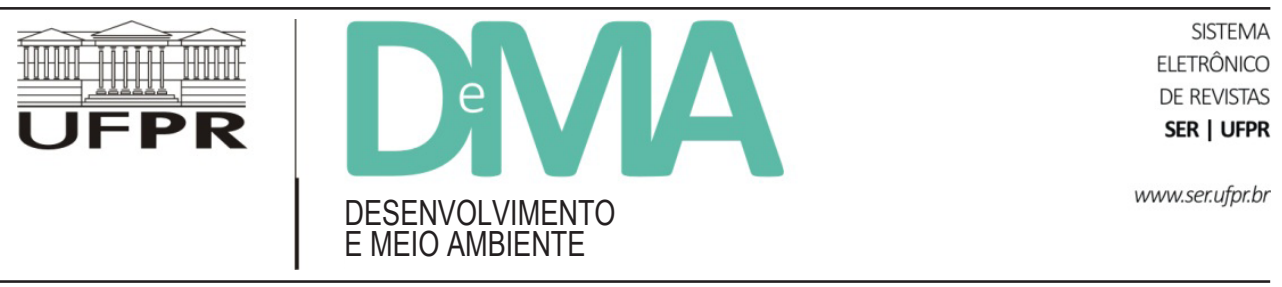

\title{
Cadastro Ambiental Rural: uma análise da nova ferramenta para regularização ambiental no Brasil
}

\section{Rural Environmental Registry: Analysis of a New Tool for Environmental Regularization in Brazil}

\author{
Sarita Soraia de Alcântara LAUDARES ${ }^{*}$, Kmila Gomes da SILVA ${ }^{1}$, Luís Antônio Coimbra BORGES ${ }^{1}$ \\ ${ }^{1}$ Universidade Federal de Lavras (UFLA), Lavras, MG, Brasil. \\ *E-mail de contato: saritalaudares@gmail.com
}

Artigo recebido em 9 de outubro de 2013, versão final aceita em 12 de março de 2014.

RESUMO

ABSTRACT

A promulgação da Lei n ${ }^{\circ}$ 12.651/12, conhecida como o Novo Código Florestal brasileiro por revogar o Código de 1965 e dispor sobre a vegetação nativa do país, ocasionou discussões e dividiu opiniões quanto à adequação ambiental das propriedades rurais. Este artigo tem como objetivo reunir e analisar informações técnicas disponíveis na literatura a respeito do novo sistema de regularização ambiental, o Cadastro Ambiental Rural (CAR). A nova lei exige a regularização ambiental aos que necessitam do acesso ao crédito rural. A legalização das propriedades em relação ao Código Florestal é crucial para a sua plena atividade, tanto do ponto de vista ambiental quanto creditício. Entretanto, a substituição do sistema cartorial pelo cadastro eletrônico cria um cenário de instabilidade jurídica, por ser um instrumento novo, ainda em fase de adoção, e até o momento sem definição clara para a sua aplicabilidade efetiva e prática. Espera-se que seja um sistema menos burocrático por ser um procedimento técnico-especializado realizado pelo próprio órgão ambiental.

Palavras-chave: Código Florestal; adequação ambiental; registro rural.

The enactment of Law No. 12.651/12, known as the New Brazilian Forest Code for repealing the Code of 1965 and laying out the native vegetation of the country, led discussions and divided opinions as to the environmental adequacy of rural properties. This article aims at gathering and analyzing technical information available in the literature about the new system of environmental regulation, the Rural Environmental Registry (CAR). The new law requires environmental regulation to those who need access to rural credit. Legalization of properties in relation to the Forest Code is crucial to their full activity, both from environmental and credit point of view. However, the replacement of the notarial system by the electronic registration creates a scenario of legal instability, as a new instrument still undergoing adoption, and so far with no clear definition for their effective and practical applicability. It is expected that the system will be less bureaucratic for being a technical and specialized procedure carried out by the environmental agency itself.

Keywords: Forest Code; environmental adequacy; Rural Registry. 


\section{Introdução}

A conservação das florestas e outros tipos de vegetação nativa é fundamental para a proteção da fauna e da flora originais de cada região. A legislação brasileira contém, dentre os principais instrumentos para assegurar essa conservação, a Área de Preservação Permanente (APP) e a Reserva Legal (RL). As APPs correspondem às "áreas protegidas, cobertas ou não por vegetação nativa, com a função ambiental de preservar os recursos hídricos, a paisagem, a estabilidade geológica e a biodiversidade, facilitar o fluxo gênico de fauna e flora, proteger o solo e assegurar o bem-estar das populações humanas". Já a RL, corresponde à

área localizada no interior de uma propriedade ou posse rural, delimitada nos termos do Art. 12, com o propósito de assegurar o uso econômico de modo sustentável dos recursos naturais do imóvel rural, auxiliar a conservação e reabilitação dos processos ecológicos e promover a conservação da biodiversidade, bem como o abrigo e a proteção de fauna silvestre e da flora nativa (Brasil, 2012a).

Como pode ser observado nas próprias definições de APPs e RLs, são áreas de elevada importância para manutenção dos processos ecológicos. Ambas prestam vários serviços ambientais, tais como: atenuam a erosão de terrenos declivosos e evitam a colmatagem dos rios, servem para conectar áreas e, consequentemente, proporcionar a diversidade gênica animal e vegetal (Metzger, 2010), funcionam como bancos de sementes de vegetação primária, refúgio para espécies migratórias, entre outros, e, portanto, devem ser preservadas.

Porém, mesmo com todos os benefícios trazidos, essas áreas têm sido bastante degradadas pelas práticas agrícolas. Como exemplificam Attanasio et al. (2006), no Estado de São Paulo, mais de $80 \%$ do território, que era recoberto por florestas, foi drasticamente reduzido nos últimos 150 anos, devido ao intenso processo de ocupação do interior paulista conduzido pela expansão da agricultura, a cerca de apenas 7\% da área do Estado. Os autores ainda afirmam que, embora protegidas legalmente desde a década de 1960, nem mesmo as Florestas de Preservação Permanente foram poupadas no processo de degradação.
Os resultados preliminares do último censo agropecuário realizado pelo Instituto Brasileiro de Geografia e Estatística (IBGE), em 2006, também divulgaram o aumento da expansão das fronteiras agrícolas, onde áreas de lavouras foram ampliadas em 83,5\% em relação ao penúltimo censo, em 1996. Enquanto as regiões Sudeste e Sul registraram os menores incrementos, de 50,4\% e $48,8 \%$ respectivamente, o Norte do país apresentou o maior aumento relativo na área de lavoura, de 275,5\%. Já as regiões Centro-Oeste e Nordeste apresentaram um crescimento intermediário de $95,6 \%$ e $114,7 \%$, respectivamente.

Sabe-se que as leis que tratam do meio ambiente no Brasil estão entre as mais completas e avançadas do mundo. De acordo com Haroldo Mattos Lemos, presidente do Instituto Brasil Programa das Nações Unidas para o Meio Ambiente - PNUMA (2009), o país mostra avanços significativos de preservação do meio ambiente, mas ainda tem muito dever a cumprir, principalmente no âmbito da fiscalização. Gomes e Martinelli (2012) retratam falhas que são reveladas no Código Florestal de 1965. Segundo estas autoras, há muito tempo essa lei vem sendo alvo de críticas, acerca de sua ineficácia no que tange à regulamentação e à fiscalização da supressão de florestas e demais formas de vegetação.

Visando solucionar as falhas de monitoramento da aplicação do Código Florestal de 1965, surge um instrumento criado pela Lei $12.651 / 12$ no âmbito do Sistema Nacional de Informação sobre o Meio Ambiente (SINIMA), o Cadastro Ambiental Rural (CAR), que visa constituir uma base de dados estratégica para o controle, o monitoramento e o combate ao desmatamento das florestas e demais formas de vegetação nativa do Brasil. Entretanto, esse instrumento tem sido alvo de críticas pela dificuldade de aplicação e tempo estendido para sua adesão. Neste contexto, objetivou-se reunir e analisar as informações técnicas disponíveis na literatura sobre o CAR.

\section{Pontos conflituosos e a importância de se proteger}

As principais discussões em torno do Código Florestal Brasileiro se pautaram na largura mínima das 
Áreas de Preservação Permanente e na anistia aos que ficaram ao revés da lei (Galvão \& Augustin, 2011). Enquanto o setor ruralista defendia a expansão do setor agropecuário para garantir a produção de alimentos, alegando que as restrições estabelecidas pela legislação ambiental impediam o crescimento econômico e a consequente competição com outros países, os ambientalistas e cientistas, como Martinelli et al. (2010), Lewinsohn et al. (2010), Sparoveck et al. (2011), defendiam que a reutilização de áreas já desmatadas e em situação ociosa já seria suficiente para atender a demanda agropecuária.

O Código Florestal de 1965 continha pontos incoerentes com a realidade, sendo imprescindível sua reformulação e atualização para que fosse mais exequível e cumprido pela sociedade (Borges et al., 2009). Segundo a Lei, aqueles que conservassem, preservassem e recuperassem as APPs teriam preferência em projetos oficiais de assistência técnica, de construção de infraestrutura, como eletrificação rural, estradas e postes, de créditos rurais e isenção de Imposto Territorial Rural (ITR). Os mesmos autores afirmam que tudo isso ficava no campo das boas intenções, pois na prática não ocorria. $\mathrm{O}$ que existia de significativo nesses incentivos era apenas a isenção do ITR, porém, o valor desta isenção era muito pequeno quando comparado com o custo de oportunidade de uso dessas áreas, ou seja, o valor por hectare que uma propriedade deixaria de recolher de imposto por manter sua APP era menor do que aquele que ela auferiria se explorasse este mesmo hectare com uma atividade silvicultural ou agropecuária. No entanto, a flexibilidade do novo Código Florestal, sancionado em 2012 sob a Lei Federal no 12.651, aliada à ausência de parâmetros para intervenção e condução de atividades em áreas protegidas, coloca essas áreas sob riscos de impactos muitas vezes irreversíveis.

A nova lei florestal possibilitou a flexibilidade dos critérios de proteção, não cabendo destacar todos, mas o essencial para que o leitor possa situar-se sobre a problemática.

\subsection{A questão da metragem da APP ciliar}

Pelo antigo Código Florestal, as Áreas de Preservação Permanente, em zonas rurais ou urbanas, ao longo dos rios ou de qualquer curso d'água, eram medidas desde o seu nível mais alto em faixa marginal. Com APP de trinta metros para rios com até dez metros de largura, cinquenta metros para rios que possuíam entre dez a cinquenta metros de largura, cem metros para rios que possuíam entre cinquenta a duzentos metros de largura, duzentos metros para rios que possuíam entre duzentos a seiscentos metros de largura, e quinhentos metros para rios que possuíam largura maior que seiscentos metros, como demonstra a Tabela 1 (Art. $2^{\circ}$ do Código Florestal de 1965; Res. CONAMA no 303 , de 20/03/2002):

TABELA 1 - Largura da Área de Preservação Permanente - APP - em relação à largura do curso d'água.

\begin{tabular}{cc}
\hline Largura do curso d'água (m) & Largura da APP (m) \\
\hline$\leq 10$ & 30 \\
$10-50$ & 50 \\
$50-200$ & 100 \\
$200-600$ & 200 \\
$>600$ & 500 \\
\hline
\end{tabular}

Pelo novo código (Art. $4^{\circ}$ da Lei $n^{\circ} 12.651 / 12$ ), a metragem permanece a mesma (Tabela 1 ), entretanto, ao invés de instituí-la desde o seu nível mais alto, o cálculo é estabelecido a partir da borda da calha do leito regular. Desconsideram, ainda, as faixas marginais dos cursos efêmeros, abrangendo somente os perenes e intermitentes.

Neste item será avaliada a questão das áreas marginais serem medidas a partir da borda da calha do leito regular ao invés do maior leito sazonal. Rezende (2013) afirma que essa mudança na medição das APPs facilitou a mensuração das mesmas, que eram muito difíceis de serem estabelecidas a partir do maior leito sazonal, e ainda defende que essa alteração era necessária para garantir a preservação de tais áreas. Contudo, a nova lei diminuiu significativamente as APPs, mesmo que a metragem tenha permanecido a mesma, deixando essas áreas sob riscos de impactos irreversíveis (Figura 1). De acordo com Miguel apud Gandolfi (2010), no Brasil, cerca de $90 \%$ dos rios possuem calha menor do que cinco metros e, dessa maneira, a proteção ficou menor ainda para rios menores, quando justamente deveria ser o contrário. $\mathrm{O}$ pesquisador ainda explica que os rios pequenos são mais frágeis, mais suscetíveis a sofrer assoreamento, e por essa razão deveriam ser mais protegidos. 


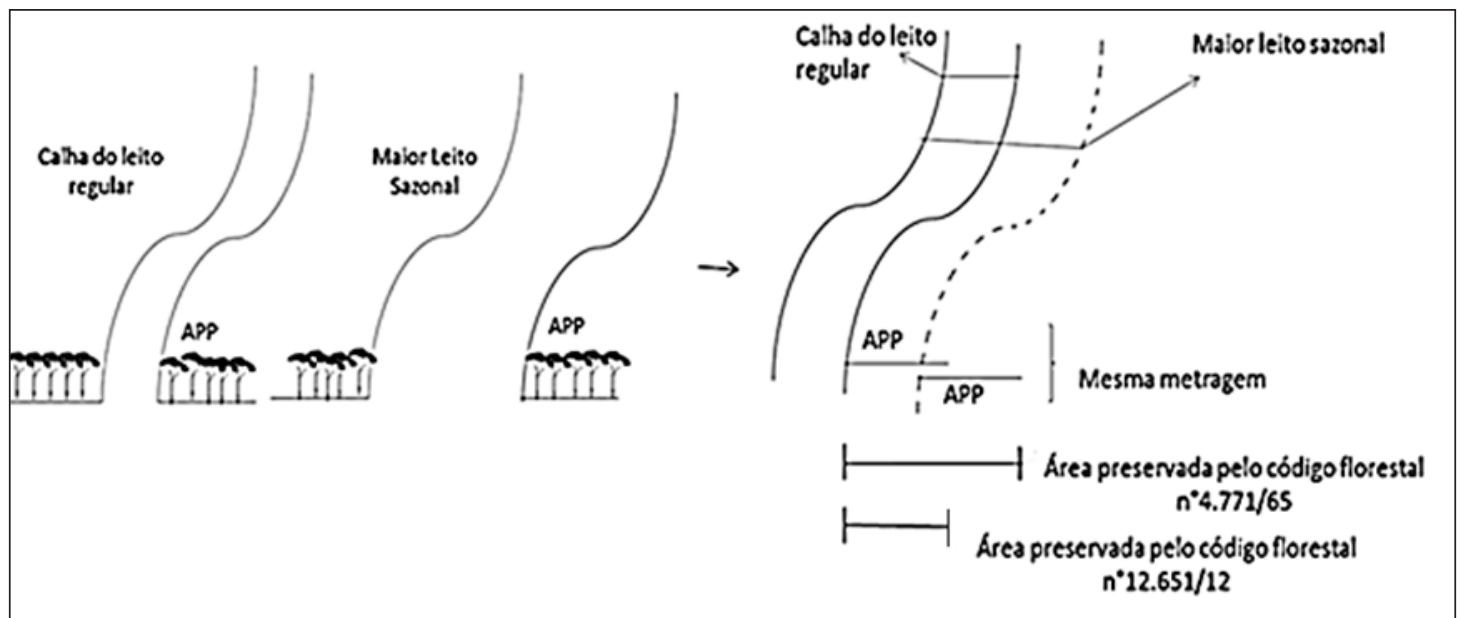

FIGURA 1 - Área de Preservação Permanente Marginal.

FONTE: Elaborado a partir da Lei nº 12.651 de 2012 - Código Florestal.

A diminuição das APPs ciliares significa perda de habitats, menor biodiversidade e instabilidade dos cursos d'água. De acordo com Skorupa (2003), nas áreas de nascentes, a vegetação atua como um amortecedor das chuvas, evitando o seu impacto direto sobre o solo e a sua compactação. Isto permite, pois, juntamente com toda a massa de raízes das plantas, que o solo permaneça poroso e seja capaz de absorver a água das chuvas, alimentando os lençóis freáticos, o que evita o escoamento superficial excessivo de água com partículas de solo e resíduos tóxicos provenientes das atividades agrícolas para o leito dos cursos d'água, poluindo-os e assoreando-os; nas margens de cursos d'água ou reservatórios, a APP ciliar garante a estabilização de suas margens, evitando que o seu solo seja levado diretamente para o leito dos cursos, atuando como um filtro ou como um "sistema tampão". E no controle hidrológico de uma bacia hidrográfica, a APP atua como um regulador do fluxo de água e, assim, do lençol freático.

\subsection{A recomposição da Reserva Legal}

Este item trata da obrigação de recomposição da Reserva Legal para aqueles proprietários que não possuem o percentual mínimo de vegetação nativa exigido por lei (Art. 12): 80\% (oitenta por cento) na Amazônia Legal; 35\% (trinta e cinco por cento) no imóvel situado em área de cerrado da Amazônia Legal; 20\% (vinte por cento) no imóvel situado em área de campos e $20 \%$ (vinte por cento) da área do imóvel localizado nas demais regiões do país.

Pela Lei $n^{\circ} 4.771 / 65$, a reconstituição da RL deveria ser feita, independente do tamanho da propriedade, mediante o plantio, a cada três anos, de no mínimo $1 / 10$ da área total necessária à sua complementação com espécies nativas, de acordo com critérios estabelecidos pelo órgão ambiental estadual competente. Esta medida poderia levar trinta anos para ser concluída. Um aspecto positivo referente à Lei $n^{0} 12.651 / 12$ é que o prazo para a recomposição da RL possui um limite menor que vinte anos, ou seja, o plantio deverá ser feito no mínimo em $1 / 10$ da área total necessária à sua complementação a cada dois anos.

Entretanto, pela mesma lei (Lei $\left.{ }^{0} 12.651 / 12\right)$, imóveis rurais que detinham, em 22 de julho de 2008, área de até quatro (4) módulos fiscais e que possuíam remanescente de vegetação nativa em percentuais inferiores ao previsto no Art. 12, podem deixar as RLs constituídas com a área ocupada com a vegetação nativa existente em 22 de julho de 2008 , vedadas novas conversões para uso alternativo do solo. Com essa medida, se 
um imóvel abaixo de quatro módulos fiscais - que, em algumas regiões do Brasil, pode atingir até quatrocentos hectares - não possuir sequer $1 \%$ de vegetação nativa para compor a Reserva Legal, poderá ele ser dispensado de cumprir com tal obrigação.

Valverde (2011) afirma que a obrigação da área de Reserva Legal é desconectada com a realidade e há dúvidas de que ela mantenha um ecossistema equilibrado, além de não ter uma localização tecnicamente definida, utilizando-se de números e critérios insondáveis.

Valverde (2013) alega também que é preciso acabar com a Reserva Legal sem prejuízo da conversão florestal, afirmando que o Brasil é o único país do mundo em que existe esta "aberração". Para o pesquisador, a RL é uma restrição imposta por ambientalistas e ONGs internacionais patrocinadas por países que veem suas indústrias comprometidas pela competitividade com o Brasil pela produção física florestal.

Já De Oliveira e Wolski (2012) e Metzger (2010) defendem a importância da reserva como instrumento para se garantir uma cobertura vegetal mínima e com isso a conservação da biodiversidade por meio da formação de corredores ecológicos e da criação de habitats para espécies vegetais e animais.

A Sociedade Brasileira para o Progresso da Ciência (SBPC) afirma que há consenso entre os pesquisadores de que a manutenção tanto das APPs como das RLs nos diferentes biomas é de suma importância para a conservação da biodiversidade brasileira. Dentre os impactos negativos da redução dessas áreas estão a extinção de espécies de muitos grupos de plantas e animais; o aumento de emissão de $\mathrm{CO}_{2}$; a redução de serviços ecossistêmicos, tais como controle de pragas, a polinização de plantas cultivadas ou selvagens e a proteção de recursos hídricos; a propagação de doenças (transmitidas por animais silvestres); a intensificação de outras perturbações (incêndios, caça, extrativismo predatório, efeitos de agroquímicos); o assoreamento dos rios, reservatórios e portos, com implicações evidentes no abastecimento de água, energia e escoamento de produção em todo o país (Silva et al., 2012).

Pode-se perceber que a RL, além de trazer benefícios para todo o ambiente, como já mencionado acima, proporciona benefícios indiretos para o proprietário rural, uma vez que os recursos naturais, como solo e água, são essenciais para a produção de agricultura, pecuária e silvicultura. A RL deve ser vista, além de mantenedora dos recursos naturais, como uma oportunidade de diversificação da produção e da renda, uma vez que, por meio de manejo e exploração sustentável, podem-se retirar e vender os produtos e subprodutos, tais como óleos, folhas, madeiras e outros.

\subsection{A consolidação de atividades em Áreas de Preservação}

O Código Florestal, Lei no 4.771 de 1965, determinava que as Áreas de Preservação deveriam ser mantidas intocadas e aqueles que instituíssem atividades nestas áreas estariam violando a legislação. A nova tutela jurídica que trata de assuntos florestais, Lei ${ }^{\circ} 12.651$ de 2012, também prediz que essas áreas devem ser mantidas intocadas, contudo, permite a continuação de atividades estabelecidas em APP até 22 de julho de 2008, sob a figura do uso antrópico consolidado.

Com essa medida, a lei reza ampla anistia aos crimes ambientais ocorridos até 22 de julho de 2008, pois aqueles pequenos proprietários possuidores de até quatro módulos fiscais de propriedade, que infringiram a lei estabelecendo atividades em locais onde não eram permitidas, estarão legalmente autorizados a continuar com suas operações. Em outras palavras, aqueles que descumpriram o antigo código estarão anistiados de pagar pelos passivos ambientais, ou seja, estarão isentos de promover investimentos e a compensação pelos impactos causados à natureza, desde que não suprimam mais a vegetação nativa após a data estabelecida.

Esta consolidação, além de ser uma anistia àqueles que desmataram e consolidaram atividades em áreas que por leis eram para ser mantidas intocadas, trouxe sérias discussões também sobre a data limite para enquadramento ao conceito. Parlamentares alegaram que a escolha foi devida ao decreto $n^{0} 6.514$, de 22 de julho de 2008, que dispõe sobre as infrações e sanções administrativas ao meio ambiente e estabelece o processo administrativo federal para apuração destas infrações. Caso tivessem escolhido a data em que surgiu a Lei de Crimes Ambientais, Lei no 9.605, de 12/07/98, teria um sentido mais plausível. No entanto, se ocorrido, as 
propriedades que estavam irregulares de 1998 a 2008 continuariam sem o "perdão" por terem ficado ao revés da lei, e assim permaneceria o grande problema das propriedades irregulares, ou seja, o passivo ambiental.

\section{Reestruturação do Código Florestal, período de adaptação e o surgimento do Cadastro Ambiental Rural no Brasil (CAR)}

Sparoveck et al. (2011) já afirmavam que a reestruturação do Código Florestal Brasileiro deixaria a desejar nas questões relacionadas ao passivo ambiental (irregularidades do passado). Os autores supracitados questionaram a hipótese de as alterações, adaptações ou regulamentações terem produzido os efeitos esperados, com base em regras tão maleáveis como, por exemplo, o cômputo da APP em RL. Este cômputo propicia o risco de o poder público não dispor de meios eficazes para controlar a contabilização das APPs computadas no cálculo das RLs, deixando a área de RL de cada imóvel variável e, portanto, difícil de fiscalizar.

Outro aspecto que Sparovek et al. (2011) chamam atenção é para a compensação das Reservas Legais em outra área de equivalência ecológica. Para os pesquisadores, essa situação parece um favorecimento ao mercado ecológico. O Novo Código permite a compensação da RL em outra área, desde que no mesmo bioma, ao invés da compensação na mesma microbacia. Sendo assim, provavelmente irá ocorrer conversão em terras melhores, que depois serão utilizadas com alta produtividade e, assim, as áreas de baixa aptidão agrícola serão mais valiosas se remuneradas pelo mercado de compensação.

Sauer e França (2012) também acreditam que as propostas do Novo Código acabam consolidando perdas passadas e mantendo riscos ambientais futuros, como, por exemplo, ampliação de atividades agrossilvipastoris em área de declive, provocando ou acentuando erosões e outros danos ambientais.

Para Paulino (2012), existe uma flexibilidade que se encontra na própria definição de Reserva Legal (área localizada no interior de uma propriedade ou posse rural, delimitada nos termos do Art. 12, com a função de assegurar o uso econômico de modo sustentável dos recursos naturais do imóvel rural, auxiliar a conservação e a reabilitação dos processos ecológicos e promover a conservação da biodiversidade, bem como o abrigo e a proteção de fauna silvestre e da flora nativa). Se o artigo 20, que determina que "no manejo sustentável da vegetação florestal da RL serão adotadas práticas de exploração seletiva nas modalidades de manejo sustentável: sem propósito comercial para consumo na propriedade e manejo sustentável para exploração florestal com propósito comercial", for interpretado ipsis litteris, não há como falar em reserva como bem conforme previsto em sua definição, "capaz de auxiliar a conservação e a reabilitação dos processos ecológicos e promover a conservação da biodiversidade, bem como abrigo e a proteção de fauna silvestre e flora nativa". Essa definição, segundo a autora, parece mais um recurso a ser explorado na ocasião oportuna, bastando recorrer à palavra manejo sustentável, expressão genérica sem qualquer demarcação precisa ao longo do texto e que abre brechas para ações devastadoras.

A expressão manejo sustentável, por ser uma expressão muito ampla, tem abrangido muitas atividades, inclusive insustentáveis. Por exemplo, uma área recém-desmatada para produção comercial, manejada de forma ordenada e racional, pode ser designada como "manejada sustentavelmente". É de convir que uma área desmatada não seja compatível com a designação "sustentável".

Sabe-se que toda mudança na legislação requer um período de adaptação para que os atores envolvidos se enquadrem nas condições estabelecidas com as novas regras, contudo, a cada reformulação esse período se estende, adiando a regulamentação do passivo ambiental. Ao tempo em que este período de adaptação à lei está se esgotando, na maioria das vezes, propostas mais flexíveis e anistiadoras são adotadas, tornando o cenário mais crítico e propício à não conformidade à legislação. Além disso, Garcia (2012) afirma que o favorecimento ao não cumprimento da legislação também se justifica pela não adequação das leis à realidade do país, associada à ausência de fiscalização.

Devido à flexibilidade no Novo Código Florestal e à importância de se proteger as áreas estratégicas para o equilíbrio dos processos ecológicos, é esperado que os imóveis rurais que se encontravam ao revés da lei regularizem seus passivos e fiquem em conformidade com a nova legislação ambiental. Para acompanhar o 
desempenho dessas propriedades, foi elaborada uma importante ferramenta para auxiliar o planejamento ambiental e econômico, o controle e o monitoramento das áreas rurais e a recuperação de áreas degradadas. Trata-se do Cadastro Ambiental Rural (CAR), um registro eletrônico obrigatório para todos os imóveis rurais do país, que tem por finalidade integrar as informações ambientais referentes à situação das Áreas de Preservação Permanente, das áreas de Reserva Legal, das florestas e dos remanescentes de vegetação nativa, das Áreas de Uso Restrito e das áreas consolidadas das propriedades e posses rurais do país.

Por intermédio do CAR, todas as informações referentes à situação ambiental das Áreas de Preservação Permanente, das áreas de Reserva Legal, das florestas e dos remanescentes de vegetação nativa, das Áreas de Uso Restrito e das áreas consolidadas das propriedades e posses rurais do país irão compor uma base de dados integrada, com fotos de satélites, disponíveis a toda população. Pode-se dizer que o CAR surge como uma possibilidade de fomento para a formação de corredores ecológicos e para a conservação dos demais recursos naturais, o que contribui para a melhoria da qualidade ambiental.

No tocante à RL, este cadastro tornou-se uma expectativa para o combate às áreas que se encontram em situações de ilegalidade, uma vez que apenas averbação em cartório não apresentou ser um mecanismo suficiente de controle ambiental. De acordo com Delalibera et al. (2008), é possível verificar, com base em diagnósticos ambientais realizados no Brasil, que são raras as propriedades rurais que possuem RL e/ou RL averbada em cartório. Sem contar as Reservas Legais que são averbadas em cartório e depois transformadas em pastos, plantações agrícolas, entre outros.

Bacha (2005), antes mesmo das considerações de Delalibera et al. (2008), afirma que não há dados sistemáticos sobre o número de imóveis rurais e a proporção deles que mantêm Reserva Legal. Os únicos dados disponíveis são os cadastros de imóveis rurais do INCRA, que são informações prestadas diretamente pelos proprietários rurais. Esses cadastros apresentam o problema de os proprietários não terem informado, em um ano-base, todos os dados sobre sua propriedade, bem como poderem excluir informações que os com- prometam. E, mesmo com os dados do INCRA, pode-se observar que desde a década de 1970 tem sido comum o desrespeito ao cumprimento da Reserva Legal. O percentual dos imóveis rurais que a cumprem é baixo (inferior a 10\%, em nível de Brasil) e, ainda assim, os proprietários não mantêm o mínimo definido em lei. Na década de 1970, o maior índice de cumprimento de Reserva Legal ocorria na Região Norte. A partir da obrigatoriedade de registrar a reserva na matrícula do imóvel, a partir de 1989, deve ter ocorrido a sonegação dessa área na mencionada região.

Bittencourt e Mendonça (2004) alertaram para importância da averbação da RL. De acordo com elas, a averbação é um procedimento importante para o planejamento do uso do solo, bem como para o manejo de ecossistemas locais. A partir desse processo, o poder público poderia orientar os proprietários rurais na formação de corredores ecológicos entre Unidades de Conservação (UCs) ou zonas de amortecimento no entorno dessas, proporcionando garantia de maiores áreas preservadas com vegetação nativa, além da estabilidade ecológica.

Com as novas regras da regularização ambiental estabelecidas pelo Decreto 7.830/12, que institui normas de caráter geral aos Programas de Regularização Ambiental, o proprietário rural fica isento do registro da RL em cartório, após a adesão ao CAR (Brasil, 2012b). Pesquisadoras como Araújo e Juras (2012) discordam da substituição do registro da RL em cartório pelo cadastro ambiental. Para as autoras, os órgãos ambientais ainda não estão estruturados para manter adequadamente o modelo proposto. Além disso, consideram que a averbação estabelece mais segurança jurídica do que o cadastro eletrônico.

Araújo e Juras (2012) afirmam também que há duvidas sobre a capacidade de o Poder Público fiscalizar as ocupações ilegais. Consideram que o controle de ilicitudes não pode ser assegurado com base numa nova lei em que o único instrumento de monitoramento, o CAR, se encontre em processo de adaptação. Alegam, inclusive, que não adianta criar leis para controlar ocupações ilegais se não houver profissionais capacitados e recursos financeiros para garantir a eficácia do monitoramento e controle dessas áreas a serem protegidas.

Por outro lado, Borges (2013) acredita que o CAR pode vir a ser um instrumento facilitador da fiscalização 
ambiental e até mesmo da gestão das propriedades nele inseridas. Para o pesquisador, muitos cadastros em cartório não estabelecem tanta segurança jurídica quanto um sistema que vai disponibilizar para o público todas as informações referentes àquela área. O ex-presidente do Instituto Nacional de Colonização e Reforma Agrária (INCRA), Francisco Graziano (2012), da mesma forma, se posiciona a favor do CAR, alegando ser uma das vantagens da nova lei florestal para facilitar a fiscalização ambiental.

Farinaci et al. (2013) também creditam importância ao Cadastro Ambiental Rural. Admitem que o monitoramento de áreas rurais por sensoriamento remoto é, sem dúvida, uma ferramenta importante para a gestão ambiental. Contudo, a inexistência de mapas de estrutura fundiária de muitos municípios dificulta essa fiscalização. Acreditam que o levantamento georreferenciado das propriedades para o registro de imóveis e o Cadastro Ambiental Rural ajudarão os municípios a contornarem este problema.

O CAR possui também uma vantagem relacionada ao mercado de cotas de Reserva Legal. O benefício mais evidenciado do novo cadastramento para os produtores rurais é que a ferramenta permite troca de informações e imagens para aqueles que precisarem empregar o recurso de Cotas de Reserva Ambiental (CRAs). As CRAs são títulos representativos de cobertura vegetal que podem ser utilizados para compensar a falta de RL em outra propriedade, ou seja, aquelas propriedades que possuem déficit de RL podem arrendar ou comprar áreas nativas daquelas que estão com superávit de reserva. Sendo assim, funciona como uma fonte de renda alternativa para quem cria, arrenda ou vende as cotas e como auxílio para aqueles que precisam regularizar suas propriedades. De certa forma, também contribui para conservação e recuperação ambiental ao atribuir valor econômico às áreas de vegetação nativa nas propriedades privadas.

Na visão de Camargo (2013), o CAR poderá ser uma importante ferramenta para gestão ambiental das propriedades rurais, no entanto, precisará de mudanças efetivas no processo de estabelecimento para não tornar-se uma ferramenta inócua. Para a assessora de política e direito ambiental, o sistema nacional que o Ministério do Meio Ambiente (MMA) está desenvolvendo apresenta fragilidades, podendo comprometer a qualidade e a efe- tividade do mesmo. Para simplificar o processo, o CAR retira a obrigatoriedade de um técnico para realização do cadastro, permitindo que o próprio produtor rural faça sua planta do imóvel com a delimitação do perímetro e das respectivas áreas de conservação diretamente sobre a imagem de satélite. Tal estratégia, por um lado, facilita a inscrição dos produtores, mas, por outro, dificulta a validação do sistema.

Camargo (2013) argumenta que elaborar plantas georreferenciadas (Art. $5^{\circ}$ do Decreto 7.830/12) não é uma tarefa trivial, principalmente considerando a necessidade de uma precisão mínima para identificar as APPs que, de acordo com a nova legislação, poderão ter dimensões a partir de cinco metros. Da mesma forma, não é simples compreender a legislação florestal, a qual possui uma série de termos técnicos e situações particularizadas, conforme desmatamento e tamanho da propriedade. Os cadastros inseridos conterão uma série de erros e imprecisões, fazendo com que o trabalho desses órgãos seja, muitas vezes, maior do que seria no caso dos cadastros serem elaborados por técnicos qualificados.

Por se tratar de uma nova ferramenta, pode-se perceber que o Cadastro Ambiental Rural gera insegurança jurídica àqueles que acreditam que a melhor forma de proteção ainda seja a averbação das Reservas Legais em cartório. Entretanto, cabe relembrar aqui que o Cadastro Ambiental Rural, além de disponibilizar imagens de satélites para auxílio em monitoramento, tem como objetivo traçar um mapa digital a partir do qual serão calculados os valores das áreas para diagnóstico ambiental. Isto deve auxiliar no controle das RL além do que ocorre por meio da averbação em cartório, cujo controle se fazia apenas em visita ao local.

A perspectiva advinda com o novo sistema de cadastramento é tornar a seguridade ambiental efetiva não só nas RLs, como também nas Áreas de Preservação Permanente, nos remanescentes de vegetação nativa, nas Áreas de Uso Restrito e nas áreas consolidadas das propriedades e posses (Figura 2). O advento para essa seguridade ambiental, com todos os trâmites de regulamentação, se assegura com o Programa de Regularização Ambiental (PRA) estabelecido pelo Art. 59 da Lei 12.652/12 e pelo Dec. 7.830/12. Este programa estabelece um conjunto de ações ou iniciativas a serem envolvidas por proprietários e posseiros rurais com o ob- 


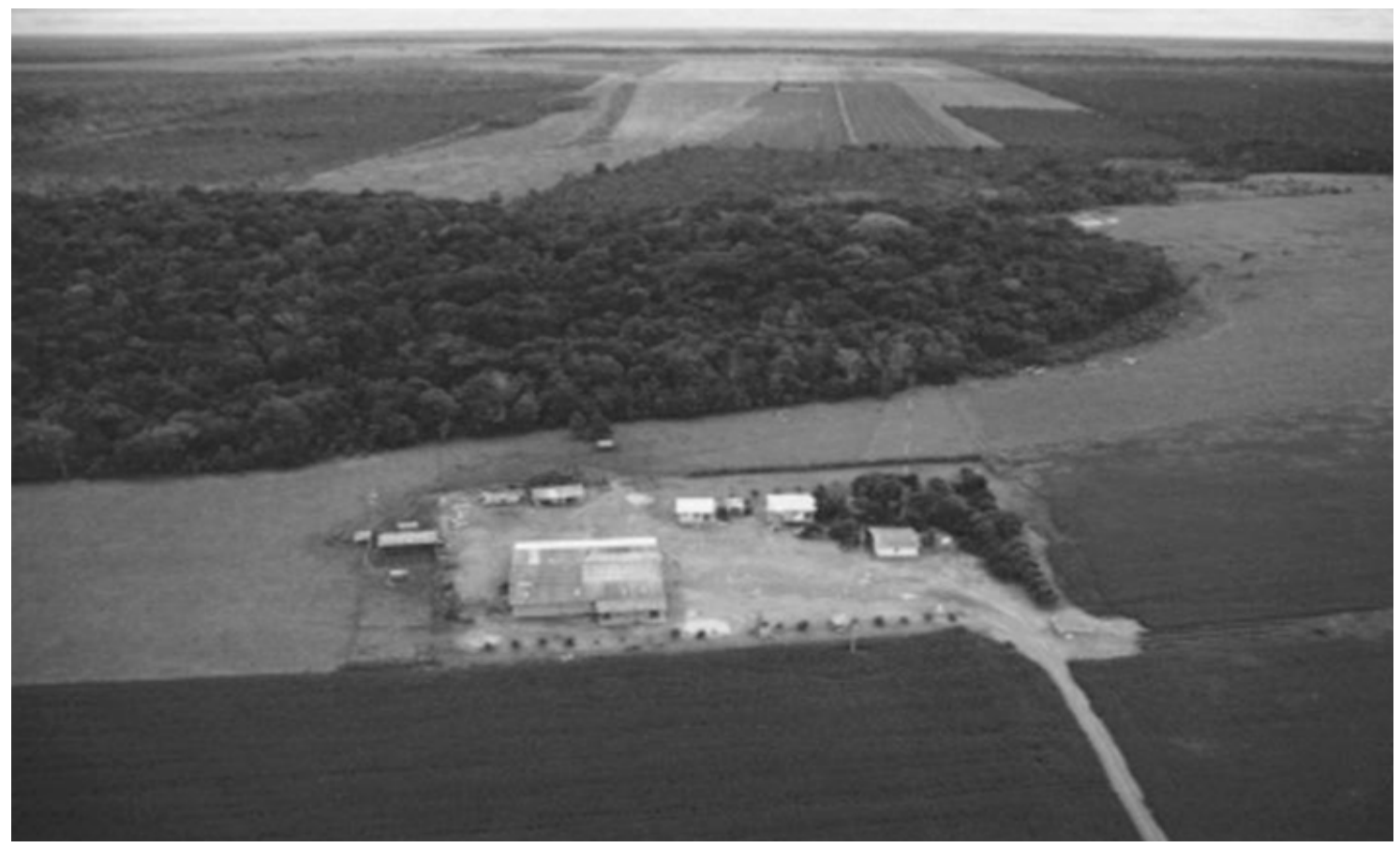

FIGURA 2 - Áreas de produção e conservação consolidadas nas propriedades rurais.

FONTE: Adaptado de: <www.agricultura.ruralbr.com.br> (2012).

jetivo de adequar e promover a regularização ambiental. O PRA é constituído de quatro instrumentos: o CAR, o termo de compromisso, o projeto de recuperação de áreas degradadas e as CRAs quando couber, sendo o CAR a chave para monitoramento e sucesso da regulamentação ambiental, visto que é por meio dele que estarão disponíveis todas as informações integradas da propriedade com subsídios de mapas e fotos de satélites.

O período estipulado para a União, os estados, órgãos estaduais, produtores rurais e outros se enquadrarem nas normas da regularização corresponde a cinco anos, iniciados a partir de maio de 2012. Sparoveck et al. (2011) acreditam que esse prazo não é suficiente para que se cumpram todas as etapas de implantação e execução desse novo modelo de gestão ambiental. Pertinente a observação dos autores, diante da complexidade do processo de regulamentação e adaptação ao novo sistema, que abrange a necessidade de vários estudos técnico/científicos e levantamento de todas as propriedades rurais. Porém, se esse prazo fosse mais extenso, os proprietários rurais poderiam apenas delongar o processo de regularização e cadastramento.

Além disso, anteriormente ao Novo Código, o CAR era vinculado ao Programa "Mais Ambiente" do governo federal e foi utilizado pelos Estados de Mato Grosso e Pará como modelo de regularização ambiental nas propriedades rurais. A ferramenta mostrou atender aos preceitos para os quais foi desenvolvida, provando sua viabilidade econômica, social e ambiental (MMA, 2013).

Atualmente, nos lugares em que o cadastro já foi implementado, pode-se observar também resultados positivos. Na Amazônia, por exemplo, em alguns pontos do Estado onde o CAR foi implantado, nota-se que o mesmo constitui-se em instrumento de múltiplos usos pelas políticas públicas ambientais e tem contribuído para o fortalecimento da gestão ambiental e o planejamento municipal, além de garantir segurança jurídica ao produtor. O Ministério do Meio Ambiente tem trabalhado para a implementação do CAR na região, por meio de projetos tais como: Projeto de Apoio à Elaboração dos 
Planos Estaduais de Prevenção e Controle dos Desmatamentos e Cadastramento Ambiental Rural; Projeto Pacto Municipal para a Redução do Desmatamento em São Félix do Xingu (PA) e Projeto de CAR, em parceria com a TNC (The Nature Conservancy), este último encerrado em dezembro de 2012 (MMA, 2013).

O CAR, por estar em fase de melhoria e implementação, não foi instituído em todo território brasileiro. Sendo assim, ainda persiste a insegurança jurídica quanto à obrigatoriedade ou não de averbar a Reserva Legal. A coordenadora do Centro de Apoio Operacional do Meio Ambiente, Suelena Carneiro Jayme, expediu informação técnico-jurídica a todos os promotores de Justiça com atuação na área ambiental, orientando sobre a manutenção da exigência da averbação de Reserva Legal como condição para a prática de qualquer ato que implique transmissão, desmembramento, retificação ou alteração de domínio do imóvel rural. Esta exigência seria necessária até haver a implementação e o funcionamento do Cadastro Ambiental Rural (CAR). Em Goiás, pelo Parecer $n^{\circ}$ 259/2012, enquanto não for desenvolvido e implantado o CAR, continua subsistindo a obrigação da averbação da Reserva Legal. Já em Minas Gerais, a Corregedoria Geral de Justiça do Estado defendeu ser facultativa a averbação em Cartório, conforme os termos do artigo 18, da Lei n ${ }^{\circ} \underline{12.651} / 12$ (Montenegro, 2013).

De acordo com Francisco Coelho, o CAR será implementado em todos os estados brasileiros até final de janeiro de 2014 (Imperatriz, 2014). Até o momento, o produtor já pode adiantar sua situação por meio do processamento das informações off-line na base de dados do cadastro ambiental, ou seja, ele consegue processar, mas ainda não pode integrar na página de dados do governo. O envio dessas informações para o órgão ambiental gera um protocolo e, assim que o CAR ficar ativo, o proprietário já estará mais próximo de fechar o seu cadastro.
Tendo em vista que o CAR será um instrumento fundamental não apenas para o PRA, mas também para outras ações governamentais de monitoramento e gestão, a preocupação central do MMA deve ser garantir um CAR de qualidade. Camargo (2013) reitera a necessidade de que os mesmos tenham o devido acompanhamento técnico, caso contrário não teremos um instrumento adequado para orientar as ações necessárias à conservação ambiental nos imóveis rurais.

\section{Consideração final}

O Novo Código Florestal teve como maior objetivo solucionar os passivos ambientais, ou seja, regularizar as propriedades que se encontravam ao revés da lei. Para isso, foram criados programas e ferramentas que melhor articulam os trâmites da regularização ambiental, sendo o CAR o mecanismo de maior expectativa quanto à eficácia na gestão e no monitoramento da recuperação dessas áreas. O cadastro ainda está em fase de ajustes e implementação, não existindo ainda um dispositivo prático para todo o país. Espera-se que seja um sistema menos burocrático, por ser um procedimento técnico-especializado realizado pelo próprio órgão ambiental. As perspectivas são boas, devido ao apreciável sucesso e à aceitação nos locais onde o cadastro foi implementado. Além disso, o CAR tem demonstrado ser um mecanismo de controle e gestão mais prático e seguro do que o sistema cartorial.

\section{Agradecimentos}

Os autores agradecem ao auxílio financeiro da Capes. 


\section{Referências}

Araújo, S. M. V. G. de; Juras, I. A. G. M. Debate sobre a nova lei florestal: análise dos textos aprovados na câmara e no senado. In: Comitê Brasil em Defesa das Florestas e do Desenvolvimento Sustentável (Org.). Código Florestal e a ciência: o que nossos legisladores ainda precisam saber. Comitê Brasil. Brasília, 2012. p. 105-116.

Attanasio, C. M.; Rodrigues, R. R.; Gandolfi, S.; Nave, A. G. Adequação ambiental de propriedades rurais, recuperação de áreas degradadas, restauração de matas ciliares. Apostila de Recuperação. Universidade de São Paulo, 2006.

Bacha, C. J. C. Eficácia da política de reserva legal no Brasil. In: Anais do $2^{\circ}$ Workshop sobre Reserva Legal, Legislação, Uso Econômico e Importância Ambiental. Piracicaba, 21 de mar., 2005.

Bittencourt, M. D.; Mendonça, R. R. Viabilidade de conservação dos remanescentes de cerrado no Estado de São Paulo. São Paulo: Annablume, FAPESP, 2004.

Borges, L. A. C. Seminário de Atualização sobre o Novo Código Florestal. Lavras: Universidade Federal de Lavras, 2013. Anotações de palestra.

; Rezende, J. L. P. Áreas Protegidas no interior de propriedades rurais: a questão das APP e RL. Floresta e Ambiente, 18(2), 210-222, 2011.

; Pereira, J. A. A. Evolução da legislação ambiental no Brasil. Revista em Agronegócios e Meio Ambiente, Maringá, 2(3), 447-466, 2009.

Brasil. Lei $n^{\circ} 12.651$, de 25 de maio de 2012. Instituiu o novo Código Florestal brasileiro. Brasília: DOU de 28/05/2012a.

. Decreto $n^{\circ} 7.830$, de 17 de outubro de 2012. Instituiu o Sistema de Cadastro Ambiental Rural, o Cadastro Ambiental Rural, estabelece normas de caráter geral aos Programas de Regularização Ambiental. Brasília: DOU de 18/10/2012b.

Camargo, F. Os rumos do Cadastro Ambiental Rural (CAR) precisam mudar. 2013. Instituto Sócio Ambiental - ISA. Disponível em: <www.socioambiental.org>. Acesso em: dez. 2013.

Conselho Nacional do Meio Ambiente (CONAMA). Resolução n. ${ }^{o}$ 303, de 28 de março de 2002. Brasília: DOU de 13/05/2002.

De Oliveira, T.; Wolski, M. S. Importância da Reserva Legal para a preservação da biodiversidade. Vivências, 8(15), 40-52, out. 2012.
Delalibera, H. C.; Weirich Neto, P. H.; Lopes, A. R. C.; Rocha, C. H. Alocação de reserva legal em propriedades rurais: do cartesiano ao holístico. Revista Brasileira de Engenharia Agrícola e Ambiental, Campina Grande, 12(3), 286-292, 2008.

Farinaci, J. S.; Ferreira, L. C.; Batistella, M. Transição florestal e modernização ecológica: a eucaliptocultura para além do bem e do mal. Ambiente \& Sociedade, 16(2), 25-46, 2013.

Galvão, F.; Augustin, C. A ciência a serviço da sustentabilidade ambiental - as unidades fitoambientais como alternativa aos impasses do novo Código Florestal. Revista Floresta, Curitiba, 41(3), 667-678, 2011.

Garcia, Y. M. O Código Florestal Brasileiro e suas alterações no Congresso Nacional. Revista Geografia em Atos, Presidente Prudente, 1(12), 54-74, 2012.

Gomes, D.; Martinelli, D. M. C. O Código Florestal e o uso da propriedade rural na perspectiva da (in)constitucionalidade da reserva legal. Cadernos de Direito, Piracicaba, 12(23), 215-233, 2012.

Graziano, F. Presidente do Greenpeace, Marina Silva e ex- presidente do INCRA listam 5 prós e contras do novo Código Florestal. 2012. Disponível em: <http://www.swu.com.br>. Acesso em: mar. 2013.

Imperatriz, I. Cadastro Ambiental começa a funcionar este mês. 2014. Disponível em: <http://www.imirante.globo.com>. Acesso em: jan. 2014.

Instituto Brasileiro de Geografia e Estatística (IBGE). Resultados preliminares do Censo Agropecuário confirmam expansão da fronteira agrícola na região Norte. 2006. Disponível em: $<$ http://saladeimprensa.ibge.gob.br>. Acesso em: dez. 2013.

Lemos, H. M. Brasil tem avanços em preservação ambiental, mas precisa melhorar. 2009. Disponível em: <http://www. uai.com.br/UAI/html/sessão_7/2009/06/05/>. Acesso em: set. 2013.

Lewinsohn, T.; Metzger, J. P.; Joly, C.; Rodrigues, R. O tiro sai pela culatra. 2010. Disponível em: $<\mathrm{http}$ ://www1.folha.uol. com.br/fsp/opiniao/fz0506201007.htm>. Acesso em: jan. 2014.

Martinelli, L.A.; Joly, C.A.; Nobre, C.A.; Sparovek, G. The false dichotomy between preservation of the natural vegetation and food production in Brazil. Revista Biota Neotropica, 10(4), 323-330, 2010. 
Metzger, J. P. O Código Florestal tem base científica? Natureza \& Conservação, 8, 92-99, 2010.

Miguel, S. Especialistas apontam falhas no novo Código Florestal. 2010. Jornal da USP, São Paulo. Disponível em: <http:// www.gvces.com.br/>. Acesso em: ago. 2013.

Ministério do Meio Ambiente (MMA). Propriedades rurais terão cadastro ambiental. 2013. Disponível em: $<$ http://www. brasil.gov.br/>. Acesso em: mar. 2013.

Montenegro, C. O panorama atual da Exigência de Averbação de Reserva Legal. 2013. Disponível em: < http://carinacgm. jusbrasil.com.br/>. Acesso em: set. 2013.

Paulino, E. T. A mudança do Código Florestal brasileiro: em jogo a função social da propriedade. Campo-Território: Revista de Geografia Agrária, 7(13), 40-64, 2012.

Rezende, J. L. P. Seminário de Atualização sobre o Novo Código Florestal. Lavras: Universidade Federal de Lavras, 2013. Anotações de palestra.

RURALBR. Ministério do Meio Ambiente autoriza compra de imagens de satélite para o Cadastro Ambiental Rural. 2012. Disponível em: <http://agricultura.ruralbr.com.br/>. Acesso em: set. 2013 .
Sauer, S.; França, F. C. de. Código Florestal, função socioambiental da terra e soberania alimentar. Caderno $C R H$, Salvador, 25(65), 285-307, 2012.

Silva, J. A. A.; Nobre, A. D.; Manzatto, C. V.; Joly, C. A.; Rodrigues, R. R.; Skorupa, L. A.; Nobre, C. A.; Ahrens, S.; May, P. H.; Sá, T. D. A.; Cunha, M. C.; Rech Filho, E. L. O Código Florestal e a Ciência: contribuições para o diálogo. São Paulo: SBPC, 2012.

Skorupa, L. A. Áreas de preservação permanente e desenvolvimento sustentável. Jaguariúna: Embrapa, 2003.

Sparovek, G.; Barretto, A.; Klug, I.; Papp, L.; Lino, J. A revisão do Código Florestal brasileiro. Novos Estudos-CEBRAP, São Paulo, 89, 111-135, 2011.

Valverde, S. R. Nossa novela Código Florestal inveja dramalhão mexicano. 2011. Disponível em: $<$ http://celuloseonline. com.br/blog/nossa-novela-codigo-florestal-inveja-dramalhao-mexicano/>. Acesso em: mar. 2013.

. O Código Florestal, sua reforma e o setor florestal brasileiro. 2013. Disponível em: $<\mathrm{http}$ ://www.cioflorestas. com.br/doc_o_brasileiro_22077.pdf >. Acesso em: dez. 2013. 